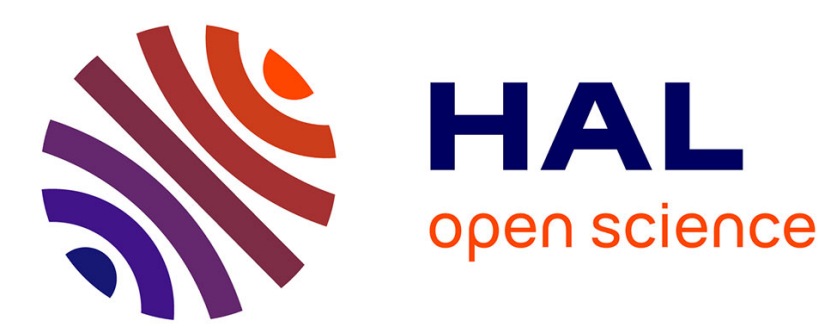

\title{
Testing Evolutionary Theory of Household Consumption Behavior in the case of Novelty - Product characteristics approach.
}

Kenza El Qaoumi, Pascal Le Masson, Benoit Weil, Aytunç Ün

\section{- To cite this version:}

Kenza El Qaoumi, Pascal Le Masson, Benoit Weil, Aytunç Ün. Testing Evolutionary Theory of Household Consumption Behavior in the case of Novelty - Product characteristics approach.. Journal of Evolutionary Economics, In press, pp.1-24. 10.1007/s00191-017-0521-9 hal-01619967

HAL Id: hal-01619967

https://hal-mines-paristech.archives-ouvertes.fr/hal-01619967

Submitted on 19 Oct 2017

HAL is a multi-disciplinary open access archive for the deposit and dissemination of scientific research documents, whether they are published or not. The documents may come from teaching and research institutions in France or abroad, or from public or private research centers.
L'archive ouverte pluridisciplinaire HAL, est destinée au dépôt et à la diffusion de documents scientifiques de niveau recherche, publiés ou non, émanant des établissements d'enseignement et de recherche français ou étrangers, des laboratoires publics ou privés. 
Testing Evolutionary Theory of Household Consumption Behavior in the case of Novelty - A product characteristics approach

Kenza El Qaoumi ${ }^{1}$, Pascal Le Masson ${ }^{1}$, Benoit Weil ${ }^{1}$, Aytunç Ün ${ }^{1}$

${ }^{1}$ CGS - The Center for Management Science, MINES ParisTech, 60 Boulevard Saint Michel, 75006 Paris, France

Corresponding author:

Kenza El Qaoumi

CGS - management of science center, MINES ParisTech, 60 Boulevard Saint Michel, 75006

Paris, France.

0033140519299

e-mail: kenza.el_qaoumi@mines-paristech.fr

JEL code of the article: E2 
Abstract: This article tests and extends the evolutionary theory of household consumption behavior, which is an alternative to neoclassical theory. Evolutionary economists offer novel approaches to the analysis of consumption behavior that emphasize the major role of learning in the evolution of consumer preferences and wants. As a possible inspiration for further progress in evolutionary thought, this paper examines the idea of consumer learning by studying the nature of what consumers should learn in the context of 'novelty'. Our empirical results regarding novelty during the learning process show that consumers learn the 'new characteristics' of consumer goods, contrary to the Lancasterian approach, which suggests that the characteristics space of goods is fixed. We show that during the process of consumption, 'consumer learning' extends the characteristics space of consumer goods; this phenomenon is far from negligible and differs across product types. Moreover, our results show that the emergence of new characteristics cannot be modeled as a Poisson process because these new characteristics exhibit clear interdependence over time.

Keywords: Evolutionary economics - Novelty - Household consumption behavior Innovation - Consumer learning. 


\section{Introduction}

A significant share of the innovation in capitalist countries takes the form of new consumer goods and services (Saviotti 2001; Ruprecht 2005; Nelson and Consoli 2010; Witt 2010). Innovation is now more consumer-oriented and intensive. This dynamic situation requires a theory that treats how consumers respond to the intensive emergence of new goods and services in a realistic way. The market must be understood as always in motion because the emergence of 'novelty' is considered a driver of economic life (Metcalfe 2001; Ruprecht 2005; Encinar and Muñoz 2006). As Witt (2009) notes, "the emergence of novelty is a pervasive feature of modern life and an important driver of economic development. New ideas, practices, and artefacts transform culture, commerce, and technology". Nelson and Consoli (2010) consider it especially important that a theory of consumer behavior be able to address continuing changes in the goods and services that are available to consumers (Nelson and Consoli 2010).

Traditionally, and for some time, neoclassical theory has assumed that households have completely stable wants and preferences; thus, only prices and incomes affect consumer choice. This assumption would be reasonable if households were exactly aware of their needs and the goods that respond to these needs. However, the emergence of 'novelty' creates new needs and affects utility functions (Nelson and Consoli 2010). The traditional approach focuses more on exchange activity than on consumption activity (Saviotti 2001; Ruprecht 2005; Nelson 2013). The evolutionary approaches account for the emergence of 'novelty' and provide new means of understanding consumer behavior. Nelson and Consoli (2010) assume that consumer wants and preferences must be formed during the process of economic development, especially with the emergence of 'novelty'. From the demand side, 'novelty' offers consumers the opportunity to systematically change their consumption behavior over time through social or individual learning (Cowan et al. 1997; Metcalfe 2001; Witt 2001; 
Nelson and Consoli 2010; Babutsidze 2011). As Saviotti (2011) explains, "The emergence of product innovations implies that consumer knowledge cannot be taken as given, new goods and services bring new knowledge and require learning”. Cowan et al. (1997), Witt (2001), and Babutsidze (2011) emphasize the major role of learning in the continuing changes in consumer preferences. Moreover, these authors discuss the different ways that consumers learn 'novelty', namely, through individual or collective learning, learning by directly using new goods (i.e., learning by consuming), and learning from social networks (Witt 2001). These different types of learning are useful to understand how consumers enrich their knowledge over time. However, we assume that the missing link in these evolutionary approaches is to clarify the nature of what consumers learn when confronted with new goods and services.

Some evolutionary economists, such as Saviotti (2001) and Backer et al. (2006), rely on the Lancasterian approach, which regards new goods as being the result of a new combination of existing product characteristics. According to this perspective on consumer learning, consumers learn new combinations of existing characteristics, even when new goods and services emerge. We call this type of learning 'recognition learning' because it allows consumers to recognize new combinations among the possible combinations of existing characteristics of goods. The evolutionary theory of household consumption behavior (Nelson and Consoli 2010) goes beyond this 'recognition learning' and suggests that new goods introduce unknown characteristics (i.e., significant changes in goods) to the market; new goods are not merely a combination of existing characteristics. For example, with current mobile phones, we can take pictures and instantly share them with others, check emails on the go, play games whenever and wherever we want, and (at the same time) communicate with others. If we compare current mobile phones with old mobile phones, we notice that new mobile phones have characteristics that did not exist before; therefore, 
'novelty' extends the space of the characteristics of cell phones. The evolutionary theory of household consumption suggests that, in the emergence of 'novelty', during the learning process, consumers learn the new characteristics of consumer goods; we call this type of learning 'extension learning'. 'Extension learning' allows consumers to discover the new characteristics of goods, whereas 'recognition learning' allows consumer to discover the new combinations of the existing characteristics of consumer goods. From a cognitive perspective, some psychology studies show that people rely on a limited number of heuristic principles to make a decision (Kahneman and Tversky 1972). People can be confronted with situations that are similar to their previous experience and thus rely on previously learned heuristics. Alternatively, people can face a situation that is so new that it requires another process, which requires people to inhibit their previously learned heuristics to acquire new ones. The literature has studied these two different forms of psychological reasoning, particularly in developmental processes. For example, Houdé's post-Piagetian approach to development shows that children either learn by re-using acquired heuristics - which is not a new milestone in their development - or they overstep developmental milestones by inhibiting learned heuristics and activating new heuristics (Houdé 2000). Brain imaging and multiple experiments have confirmed the validity of this approach (Houdé and Borst 2014). Research has also observed such behavior in adults. Several studies have demonstrated the "lure of the unknown", i.e., they show that the unknown provokes a specific (and very efficient) form of learning (see, for example, Bunzeck and Düzel 2006; Knutson and Cooper 2006). In 'recognition learning', consumers need only their current knowledge to recognize the new combinations of the existing characteristics of consumer goods. However, in 'extension learning', consumers use multiple cognitive functions, such as encoding information, predicting uncertain values, and updating knowledge (Bartels and Johnson 2015). For example, learning that a new car has a high-performance engine that pollutes less is not the 
same as learning that a car is autonomous and can park itself. In learning that a new car has a high-performance engine, consumers need only engage a limited cognitive function, namely, recognizing new combinations of existing knowledge. However, in learning that a car is autonomous and can park itself, consumers likely engage multiple cognitive functions to learn new meanings, uses and values of new consumer goods. Despite the notable differences between these types of learning, they have often been conflated in evolutionary approaches. A potential explanation for this failure to differentiate between the two is that extension learning is negligible compared with recognition learning. Therefore, we wish to analyze and measure what types of characteristics (new or otherwise) consumers must learn and the relative intensities of extension learning and recognition learning that products require.

Our research tests and extends the evolutionary theory of household consumption behavior (Nelson and Consoli 2010) by clarifying the nature of what consumers should learn in the context of 'novelty'. Our first hypothesis (H1) suggests that consumers should learn new characteristics of consumer goods or services, contrary to the Lancasterian assumption (H0). In our empirical work, we measure the number of new characteristics of various consumer goods over a long period of time. We demonstrate, first, that there is a meaningful number of new characteristics for all the products we study and, second, that this number also differs significantly across products. Moreover, our data analysis uncovers the dynamics of the emergence of new characteristics. We discuss one classical (but never tested) assumption that involves the dynamics of the emergence of new characteristics: it is usually assumed that this emergence follows a Poisson process, i.e., a process whereby the events considered are independent over time. Our data show that there is interdependence among the new characteristics that emerge in one period and some of the new characteristics that emerge in subsequent periods. This finding supports evolutionary models contending that learning provokes intertemporal interdependence. 
In the following section, we will briefly summarize the literature on the evolutionary theory of consumption behavior and consumer learning to introduce the research framework. Then, we will explain the research methodology we employ. Next, after presenting the findings, we will discuss the results. Finally, we will present the conclusions and discussion.

\section{Literature review and hypotheses: Beyond the Lancaster assumption and Poissonian models}

\subsection{The current status of the evolutionary approach as applied to consumer behavior}

Over the last forty years, a strong tradition of research on innovation has focused on the Schumpeterian model of economic growth. According to Schumpeter, the introduction of new products and continuous improvements in existing products lead to economic dynamics. Therefore, several scholars have developed theoretical structures that have proven useful to understand the economy, where innovation-driven change is the rule rather than the exception (Nelson and Winter 1982; Rosenberg 1982; Dosi et al. 1988; Freeman and Soete 1997). These scholars focused especially on the "generation side" of innovation and relatively neglected the demand side (i.e., consumers' behavior and learning processes). The reason for this traditional research orientation may be that researchers suppose that demand systematically absorbs variety and novelty in the market because consumers know well their wants and needs. Nevertheless, considerable progress has been made in addressing consumer behavior concerning the emergence of 'novelty' (Saviotti 2001; Ruprecht 2002; Nelson and Consoli 2010).

In our literature review, we build on the evolutionary approach to consumer behavior. This evolutionary approach (Langlois 2001; Saviotti 2001; Witt 2001; Nelson and Consoli 2010) departs from neoclassical economics, which as summarized by Nelson and Consoli 
(2010), assumes that households have stable, well-defined utility functions and act as "utility maximizers". Such an approach could can be perfectly adequate in the context of small changes in goods and services and if consumers have considerable experience and know well their wants and preferences. The neoclassical approach ignores the uncertainties and unknowns associated with 'novelty' and the time required for consumers to make significant changes in their behavioral patterns. This traditional approach focuses on transactional activity and ignores consumption activity per se. By contrast, Evolutionary Consumption Theory accounts for how consumers respond to new goods and services and suggests that consumer behavior is in continuous change that involves 'consumer learning'. Therefore, rather than focusing on transactional processes, the evolutionary approach examines the learning processes that determine consumer choice (Ruprecht 2002), especially in the case of 'novelty'. The evolutionary theory of household consumption behavior reinforces other evolutionary ideas such as Saviotti's perspective (2001). This perspective assumes that consumers' wants and preferences cannot be taken as given because they must be formed during the process of economic development, not only through the emergence of new goods and services but also through the 'learning process' (Metcalfe 2001; Saviotti 2001; Witt 2001; Babutsidze 2011).

The evolutionary theory of household consumption behavior emphasizes the major role of learning that allows for changes in consumer preferences. Some evolutionary economists study the different ways in which consumers learn 'novelty'. The literature reports that consumers learn from their own experiences by directly using consumer goods or from their interactions with their social environment. Nelson and Consoli (2010) recognize that the learning process changes the cultural and social attitudes of consumers and facilitates the widespread diffusion of new goods. The evolutionary approach proposes two essential ideas. 1. Consumers do not have well-defined preferences over goods and services that they 
have never experienced. 2. Changes in consumer wants involve a consumer learning process when a consumer confronts the emergence of new goods and services. Without learning, consumer knowledge will be limited; consequently, the rate of adoption of any new good or service will be slow (Saviotti 2001). In the following section, we discuss what consumers should learn concerning 'novelty', and then we distinguish different consumer learning approaches.

\subsection{In the case of novelty, consumers learn new characteristics of consumer goods}

\subsubsection{Consumer learning: A key factor in market dynamics}

The evolutionary approaches identify the mechanisms that drive the evolution of consumer preferences. These approaches emphasize the major role of consumer learning in changing the consumption activities and cultural and social references of consumers (Nelson and Consoli 2010). Moreover, these approaches assume that consumers' limited knowledge will decrease the rate of adoption of any new good or service (Saviotti 2001), which is why learning plays a major role in enriching consumer knowledge and ensuring that the market remains dynamic. Metcalfe, Witt and Cowan discuss and explore how consumers can enrich their knowledge. Therefore, in the literature on 'consumer learning', we distinguish two major types of 'learning'. 1. Learning by consuming (analogous to the learning by doing of Arrow 1962) means that consumers acquire skills during the consumption process by directly using new goods and services (i.e., consumer experience). 2. Learning from social interaction means that consumers obtain skill spillovers from their social environment (Cowan et al. 1997; Metcalfe 2001; Witt 2001, 2010; Nelson and Consoli 2010). In a social context, Cowan and Swan (Cowan et al. 1997) demonstrate that popular or unpopular reference groups influence the consumption behavior of other people. Moreover, Witt (2009) supposes that 
consumers gain recognition through the type of consumption they choose (i.e., status recognition, targeted groups). A significant number of studies discuss consumer learning by explaining how consumers learn 'novelty'; however, these studies do not provide much insight into what consumers should learn from their individual learning or social interactions. However, recent works have shown that learning may differ substantially depending on what must be learned. For this reason, our question is, what must consumers learn in the case of 'novelty'?

In the following section, we will distinguish two different learning approaches. The first is linked to the Lancasterian approach and assumes that in the context of 'novelty', consumers learn about an improved version of previous generations of goods. The second approach is linked to the evolutionary theory of household consumption and suggests that in the context of 'novelty', consumers learn about new generations of goods, which add unknown characteristics to the market.

\subsubsection{Extension consumer learning: Consumers learn the 'new characteristics' of consumer} goods

Nelson and Consoli (2010) rely on the Lancasterian framework (Lancaster 1966b) by using a multi-dimensional concept of goods (Ruprecht 2005; Nelson and Consoli 2010) and assume that some new consumer goods are considered substitutes for older goods (i.e., a combination of existing properties). However, these authors suggest that these types of goods cannot enrich consumer knowledge. Thus, for Nelson and Consoli (2010), 'novelty' provides new dimensions of consumer goods. Using mobile phones as an example, they note, “... it is clear that the new versions of cell phone equipped with cameras and access to the internet has provided a means of communication and a mode of access to arrange information that was not available before ..." Nelson and Consoli (2010) suggest that in the context of novelty, 
during the learning process, consumers learn the 'new characteristics' of consumer goods. This assumption follows the Schumpeterian approach (Schumpeter 1934, 2005; Nelson 2012; Becker et al. 2006, 2012) and assumes that development and novelty should extend the list of characteristics (see the definition of development as a revision of all parameters of economics $)^{1}$. The evolutionary theory of household consumption assumes that the emergence of 'novelty' requires a form of consumer learning that we call 'extension learning', as consumers must extend their frame of reference to consume the new product (e.g., evaluate, buy, use). 'Extension learning' allows consumers to discover the new properties of consumer goods that did not previously exist; for example, the characteristics space of mobile phones is continually extended by the addition of new characteristics. Using current mobile phones, we can take pictures and share them instantly with others, check emails on the go, play games whenever and wherever we want, and simultaneously, communicate with others.

Nelson and Consoli's assumption challenges the Lancasterian approach that relies on the clear hypothesis that the list of characteristics is fixed (Lancaster 1966a). Lancaster assumed that new goods can be regarded as a combination of existing characteristics in new proportions. Lancaster's model is valid for an expansion of the space of goods from $n$ to $n+1$ under the assumption that the space of characteristics has a constant dimension. The Lancasterian approach assumes that consumers learn new combinations of existing characteristics, even in the context of the emergence of new goods and services. This type of learning is called 'recognition learning' because it allows consumers to recognize new combinations among the possible combinations of the existing characteristics of goods. Adopting cognitive approaches, some psychology studies suggest that people rely on a limited number of heuristic principles to make a decision (Kahneman and Tversky 1972) under 'recognition learning', and consumers need only their current consumption knowledge

\footnotetext{
1 In Development, Schumpeter describes the general phenomenon of development as a discontinuity that appears because of the emergence of novel phenomena. Schumpeter adds precision by defining development as a change in vector norms in such a way that this transition cannot be decomposed into infinitesimal steps. (Schumpeter 1934) 
to recognize the new combinations of the existing characteristics of consumer goods. In 'extension learning', consumers use multiple cognitive functions. In the 'learning' literature, these two types of learning are often conflated with one another; therefore, this paper intends to test them to clarify the nature of 'consumer leaning' with respect to the emergence of 'novelty'. Therefore, our first hypothesis (H1) challenges the Lancasterian assumption (H0), as previously explained:

Hypothesis 1: there are products for which new characteristics emerge over time.

\subsubsection{Consumer learning: The emergence of new characteristics differs across products}

We can be more precise concerning hypothesis 1. As explained above, the evolutionary approach to household consumption suggests that 'novelty' continually produces new characteristics of consumer goods that were previously unknown to consumers (Nelson and Consoli 2010). Furthermore, we wish to enrich this assumption by studying the emergence of new characteristics of different consumer goods. According to Lancaster (1966a), new goods can be regarded only as a combination of existing characteristics in new proportions or as an improvement in the performance of certain characteristics. Lancaster's model accommodates the existence of revolutionary goods that can integrate new characteristics, but for Lancaster, this phenomenon was very rare and limited over time (Lancaster 1966a). Contrary to the Lancasterian assumption, evolutionary approaches (Cowan et al. 1997; Metcalfe 2001; Witt 2001, 2010; Nelson and Consoli 2010) suggest that the appearance of 'novelty' is frequent, not rare. Nelson and Consoli (2010) use the expression 'continuing introduction of new goods' or 'continuing changes in the goods and services available to consumers' to designate the frequent emergence of new characteristics of consumer goods. Therefore, we must demonstrate that the number of characteristics that 
emerge over a given period is not negligible compared with the number of known characteristics over a given period.

We can test this idea using a simple model. We consider a consumer who knows the characteristics of a product $\mathrm{P}$ at time $\mathrm{t}, \mathrm{P}_{\mathrm{t}}$; at a later period, $\mathrm{t}+\mathrm{t}$, this consumer buys the product $\mathrm{P}_{\mathrm{t}+\mathrm{n}}$. At time $\mathrm{t}+\mathrm{n}, \mathrm{P}_{\mathrm{t}+\mathrm{n}}$ has $\mathrm{n}_{\mathrm{n}}$ new characteristics and $\mathrm{n}_{\mathrm{o}}$ known characteristics. We consider $\mathrm{p}_{\mathrm{t}+\mathrm{t}}=\mathrm{n}_{\mathrm{n}} /\left(\mathrm{n}_{\mathrm{n}}+\mathrm{n}_{\mathrm{o}}\right)$ to be the proportion of new characteristics in the total number of characteristics that are used to characterize the product at time $t+t$. We consider $n_{n}$ to be negligible if $\mathrm{p}_{\mathrm{t}+\mathrm{t}}$ is significantly different from 0 . Because we wish to reject $\mathrm{H} 0$ in the most demanding situation, we choose $\mathrm{t}=$ one year. (If we reject $\mathrm{H} 0$ in this case, we also reject it in all situations that are longer than one year - which corresponds to a customer who renews his product every year.) Therefore, H1.1 is the following:

Hypothesis 1.1 (H1.1): in a one-year time period for a given product type, the proportion of new characteristics is significantly different from $0 \%$.

This measure will also allow us to compare the proportion $\mathrm{p}_{\mathrm{t}+\mathrm{t}}$ of new characteristics for different consumer goods. Intuitively, we believe that this proportion may differ across product types. Therefore, we have an additional hypothesis, H1.2:

Hypothesis 1.2 (H 1.2): the proportion of new characteristics that emerge in one product type over one year can differ significantly from that of other product types.

Thus far, we have summarized the evolutionary approach to household consumption and addressed what consumers learn with respect to 'novelty'. We suggested that in the case of 'novelty', consumers continually learn the new characteristics of goods, and we called this 
"extension learning". In the following section, we will discuss the mechanisms that allow the sustainable emergence of new characteristics of consumer goods.

\subsection{The emergence of new characteristics of consumer goods exhibits clear interdependence} among the new characteristics

We have suggested that the emergence of new characteristics is frequent, and we wish to discuss and explore the mechanisms that influence the permanent emergence of new characteristics. How can we model this process of emergence? A classical model of emergence is the Poisson process (see the model of Romer (1990) and that of Aghion and Howitt (1992)). This model assumes that the generation of 'novelty' follows a random sequence and depends on market constraints or new product development (Schmookler 1966; Mowery and Rosenberg 1979; Dosi 1982; Stefano et al. 2012). Thus, on the one hand, the level of new product development adjusts to satisfy consumer wants, and on the other hand, consumers adjust their level of wants by learning from new consumer goods on the market. Either consumer wants emerge at a Poisson rate (which implies firm learning and the emergence of new characteristics), or firms offer new characteristics at a Poisson rate, and consumers learn and adapt their wants. In this case, we have that wants $\rightarrow$ characteristics or that characteristics $\rightarrow$ wants; however, we never have that wants $\rightarrow$ characteristics $\rightarrow$ wants $\rightarrow$ characteristics. Therefore, the characteristics that emerge at time $t$ are independent of all characteristics that have previously emerged.

Following the many models that include learning processes (see, in particular, Iansiti and Clark (1994) who explicitly mention this point; see also Witt 2001), we assume that the process of the emergence of 'novelty' cannot be memoryless and that past 'novelty' can influence the emergence of future 'novelty'. This approach excludes the Poisson model and exhibits interdependence among successive 'novelties' over time. In the context of novelty, 
extension learning allows consumers to learn the new characteristics of goods (Nelson and Consoli 2010), and consequently, they update their consumption knowledge and increase their level of want. In this learning process, the Poisson models implicitly assume that consumers "adapt" to the product, i.e., their level of wants adjusts to the level of characteristics. However, this assumption is restrictive: a general model of learning assumes that learning can go beyond adaptation. Consumers will, for example, discover that the product has drawbacks and limitations, and in this case, their level of wants can exceed the level of product characteristics. We call this phenomenon 'consumer overlearning' because consumers not only search to adjust their wants to the supply but also create an imbalance between supply and demand by increasing the level of their wants. In 'overlearning', consumer wants exceed the current market supply. Thus, firms provide new characteristics to satisfy new consumer wants. Conversely, when a firm offers a product that is does not satisfy consumer wants, the firm will learn to introduce a better product. Here, again, we do not assume that firms exactly satisfy consumer wants. There is also 'overlearning' on the firm side. The firm offers a product with characteristics that did not exist before and exceeds consumer wants. Again, this imbalance between demand and supply leads to the continual emergence of new characteristics.

In this process, the characteristics of products at time $t$ imply new consumer wants at time $\mathrm{t}+\mathrm{t}$, and these new wants imply new characteristics at time $\mathrm{t}+\mathrm{t}+\mathrm{t}$ '. Therefore, the characteristics emerge at a time that depends on the characteristics that emerged previously. There is a relationship among the characteristics that emerge over time.

Figure 1 below summarizes this overlearning process. As long as we have an imbalance between wants and supply, we will have a sustainable emergence of new characteristics.

Thus, we have the following model: 
- We assume two learning actors: 1. Firm (supply side) 2. Consumer (demand side)

- We assume imbalance: At time ' $t_{0}$ ', the existing characteristics are below or above the level of consumer wants

- Learning: 1. Consumers learn from product characteristics when wants are below the level of product characteristics.

2. Firms learn from consumer wants when the characteristics of their products are below consumer wants.

We assume that learning is not optimal, and we will never have the following:

Level of wants $=$ Level of satisfaction given by the characteristics.

- A direct consequence of this model is that there appear sequences such as new characteristics $=>$ consumer overlearning $=>$ high level of $\mathrm{W}=>$ firm overlearning $=>$ new characteristics, etc.

Therefore, our hypothesis $\mathrm{H} 2$ is as follows:

Hypothesis 2 (H2): There is an intertemporal interdependence among the new characteristics that emerge over time.

If this hypothesis is confirmed, the learning patterns can be observed in the sequences of characteristics. We may observe, for example, the sequences of new characteristics of consumer goods illustrated in figure 2 below. For a product of type $\mathrm{P}$ at $\mathrm{t}+1$, a new product introduces new characteristics, "Characteristics 5 and 6" (C5 \& C6), that relate to previous characteristics: $\mathrm{C} 1$ for $\mathrm{C} 5$ and $\mathrm{C} 3$ \& $\mathrm{C} 4$ for $\mathrm{C} 6$. Another example is in $\mathrm{t}+2$, where $\mathrm{C} 8$ relates to $\mathrm{C} 6$; this relationship means that consumers in $\mathrm{t}+1$ overlearned from $\mathrm{C} 5$, and they wanted new characteristics for this good. Then, in $t+2$, the supply side produces C8. The interdependence among the new characteristics shows that there is a chain reaction effect that 
links some new emerging characteristics to the old characteristics. We use the term "chain reaction" because we assume that old characteristics influence the appearance of new characteristics, similar to a chain reaction in chemistry and physics. A chain reaction is a sequence of reactions whereby a reactive product causes additional reactions.

\section{Research methodology and empirical material}

To test the hypotheses, we developed a tool to capture the emergence of new characteristics of consumer goods and to map the interdependence among these characteristics.

\subsection{Research approach: A new tool to quantify new characteristics of consumer goods}

\subsubsection{Quantify new characteristics of consumer goods}

Our objective is to test the evolutionary theory of household consumption. Therefore, we are interested in the characteristics of consumer goods from the demand side. We wish to capture the characteristics that influence household consumption preferences. Goods contain possess properties; characteristics are the properties that are relevant to consumer choices (they have an economic effect). "Any good possesses an enormous number of physical properties: size, shape, color, smell, chemical composition, ability to perform any one of a variety of functions, and so on. Because not all properties will be relevant to choice, we shall henceforth use the term characteristics for those objective properties of things that are relevant to choice by people" (Lancaster (1971)).

We wish to capture the evolution of the characteristics space of products; therefore, the following requirements are necessary: 
1. We need an observation of the characteristics in the Lancaster sense, i.e., product features that affect consumer choice. This observation should focus only on the characteristics that have economic effects on consumption (for example, some "hidden" technical features should not be included in the list of Lancasterian characteristics). The observation should be made by an objective observer; particularly, one should avoid certain features of advertisements that one cannot be certain play a role in consumer choice.

2. The observation should be made on a representative sample of products of a given product type at a specific moment. Merely using a random sample of products drawn taken from a supermarket would be far from sufficient. Only considering products that are offered at a product fair does not guarantee a representative sample of retail offerings. The sample should be representative of the products that the consumer is likely to encounter when he or she seeks to buy a product of this type.

3. The data should be comparable over time and across product types and without significant bias.

A priori, these requirements are extremely difficult to meet. Let us first analyze the methods applied thus far to analyze product features.

\subsubsection{Different methods to quantify 'novelty'}

In the economic and management literature, we find many quantitative measures to capture new consumer goods and services. Some of these measures use specialized magazines $^{2}$ to collect innovation data that experts then validate to complete the database;

\footnotetext{
2 Electrical Review; Food Trade Review; Glass, Pharmaceutical journal; Process Engineering; Body Magazine; Freight Management; Chemist and Druggist; International Dyer; Metal Working Production; Aircraft Engineering; Wood Worker; Banker; Control and Instrumentation
} 
other measures use manufacturers' sales brochures. The first method, used by Kleinknecht et al. (1993) and Coombs et al. (1996), captures new goods and services for a short period of several months by sampling the new goods from the new product announcement sections of technical and trade journals. This method requires the intervention of many consumer goods, innovation and marketing experts who should verify and complete, if necessary, the collected list of new goods. Such expert intervention can influence the objectivity of information (i.e., experts' assessments of the degree of the novelty of the goods can be differ). The second methodology is used by Sanderson and Uzumeri (1995) and captures the variety and new features of personal portable stereos. They use manufacturers' sales brochures to capture the new characteristics of personal stereos. This method obtains the manufacturers' perspective on the properties of new products. These properties may be significant on the part of the firm, but they may not be significant to consumers. These two methods are useful; however, they are incapable of meeting our specific data needs, namely, objective data, characteristics with that have an economic effect on the demand side, a data source with several consumer goods, and a long time period. Thus, to construct our database, we develop our own tool to capture the emergence of new goods characteristics that satisfy the previously mentioned requirements.

We seek to quantify new characteristics of consumer goods. According to Lancaster (1971), goods contain many properties, but he defines characteristics as properties that are relevant to consumer choices. As Lancaster explains, product characteristic evaluations are performed frequently by consumer guides, which regularly synthesize all existing products and compare them with well-identified characteristics that are considered critical in determining the consumer's choice. This method quantifies the characteristics of consumer goods that have economic value. Following the Lancasterian perspective, we develop our tool to collect new goods characteristics by constructing our database using consumer reports. 
This brief review emphasizes that it is difficult to identify a method that meets our requirements. To do so, we would need to select a team of market analysts who analyze markets, trends, consumption, retail, journals and magazines. Then, we would have to repeatedly select samples of products by following a clear, rigorous and stabilized method and analyze the products to extract the Lancasterian characteristics with an explicit, stabilized, and rigorous method. We would need to regularly perform these actions over a long period for several product types. This effort would require several years of research and considerable funding, which is impractical. In this paper, we instead rely on another method: we use consumer guides (i.e., consumer reports) following Lancaster's advice (1966b): "Organizations such as the Consumers Union exist to provide more objective information on characteristics than is easily available elsewhere" (Lancaster 1966b).

We will demonstrate that using consumer guides meets our requirements.

\subsection{Data collection: Consumer guides as a database}

Consumer guides provide an important flow of information. These consumer reports regularly synthesize a representative sample of existing goods and compare this sample using well-identified characteristics that are considered critical in determining a consumer's choice. We based our empirical work on the results of tests from analyses of consumer goods by the French Consumer Union "Union Fédérale des Consommateurs". These results have been published periodically since 1961 in "Que Choisir?" - the French equivalent of the American magazine Consumer Reports. These reports include detailed tabulations of the characteristics of the goods that are tested.

Let us check our requirements. The following elements are based on interviews and inquiries that were conducted at Que Choisir by one of the authors ( 5 interviews with experts in product evaluation and an archivist). 
Feature 1: Experts observe product characteristics; these experts may rely on laboratories and benchmarks to be able to objectively describe some characteristics. The consumer guide regards its mission as focusing solely on the characteristics that affect consumer choice (as noted in the Consumer Guide Chart). More important, because consumer guides are prescribers, the characteristics listed by consumer guides will become references for consumers.

Feature 2: Experts who are extremely knowledgeable about the products and markets concerned construct a product sample. These experts read all available market studies; they attend fairs and visit supermarkets and retail shops. These experts are in contact with producers and firms to understand the products to the greatest extent possible. However, these experts are organized to be independent of firms - to this end, they have a specific governance and funding logic (no funds come from companies or the state; the governance structure is associative).

Feature 3: The same Consumer Guides have covered the same products for decades. Turnover is very low. The same experts have been responsible for analyzing products over long periods of time. A Consumer Guide internal chart and other managerial methods (education programs) help to form a shared logic of characteristic evaluation. Therefore, the data can be comparable over time and across different product types.

\subsection{Identifying new characteristics}

The database provides data on characteristics. We had to develop a method to identify, in each time period, the characteristics that were known in past studies and those characteristics that are new.

Our method: First, we selected four different types of products (Mobile phones, Irons Vacuum cleaners, and GPS - 'Global positioning Systems' - devices). Second, we collected 
their characteristics over a long time period (1962-2014), as shown in table 1 below. For each characteristic, we analyze whether it existed before, accounting for minor semantic changes. This analysis was conducted separately by two expert evaluators and two additional independent experts, who randomly verified some evaluations. There was high correlation across all four evaluations. We then count the new characteristics of each good (see the table below). Finally, we analyze the interdependence between the new and the old characteristics by determining whether the new and the old characteristics are related. To capture the interdependence among the new characteristics, we follow the evolution of each new characteristic over time by reading the detailed information on each characteristic in the texts that complement the characteristic tables.

\subsection{Specification of the methodology: Strengths and weaknesses}

This method is effective at capturing the characteristics of consumer goods (and economic effects) over long time periods, but it has both strengths and weaknesses.

Methodology's strengths: Our quantitative method uses consumer guides that can capture consumer goods' characteristics that have an economic effect because these guides precisely identify the characteristics of consumer goods that are relevant to choice. These consumer guides examined consumer observations for over fifty years, and they continually conduct specialized studies to understand consumer needs. Consumer guides continually test many different consumer goods, with more than 600 products tested continuously (e.g., mobile phones, irons, GPS devices, vacuum cleaners, food, tires, appliances, strollers, bikes). The consumer guides provide detailed lists of the characteristics that are significant to consumers; these characteristics are observed and measured. However, consumer guides cannot test all products on the market because there are many brands and many products from each brand. Therefore, consumer guides' marketing and purchasing specialists select a 
sample of consumer goods that adequately represents the entire market of consumer goods (e.g., Mobile phones, Irons, Vacuum cleaners, GPS devices). This selection is based on not only the entire range of market studies that are available in each time period but also on regular visits to business fairs and supermarkets. Consumer guides are independent organizations; they are not advertising for brands. Consumer guides conduct tests on different brands to compare them; therefore, they generally provide information not for the benefit of any brand or product but only for the benefit of consumers. With consumer guides, we have access to high-quality information provided by experts who are among the most qualified in their field for each product type. The experts rely on rich sources of information or develop their own measurement instruments to test different products in their own laboratories. In addition, the guides guarantee the same quality of data over time because they tend to maintain, over long time periods, the same rules, the same editorial logic, and the same approaches to analyze the market. Consumer guides are an accessible source of information and provide a detailed list of consumer goods characteristics; every year, we find tests of goods that give information that corresponds to consumer needs (economic value). Consumer guides are accessible and cover a long period of time.

Methodology's weaknesses: This method captures the characteristics of consumer goods but only the characteristics of goods that are sampled in the consumer reports. This method does not capture all of the possible new characteristics of goods; consumer guides publish only the significant characteristics of products that have economic effects. For example, concerning mobile phones, here, we capture 82 new cumulated characteristics from 1996 to 2013, and these characteristics are only significant to "Que Choisir". However, there may be more than 82 new cumulated characteristics if we were to consider other informational references (i.e., commercial brochures). For example, some new commercial features that are proposed by only one product are not included in the tables. Therefore, there 
is a negative bias: we systematically under-evaluate the number of new characteristics. However, our goal with this method is not to capture all existing new characteristics. The objective of this paper is to demonstrate the emergence of the new dimensions of goods (i.e., the evolution of characteristics) by exploring the extension of the characteristics space.

\section{Main results: Expansion of the characteristics space and learning process}

\subsection{The evolution of the characteristics of consumer goods over time}

Our empirical results show that the characteristics space of the various selected goods exhibits continual change through the addition of new characteristics over time. Here, we present the results for Mobile phones (figure 6), Irons (figure 7), Vacuum cleaners (figure 8), and GPS devices (figure 9). The frequency of new characteristics reaches up to 6 new characteristics per year for mobile phones over a 17-year period (1996-2014), 2 new characteristics per year for Irons during the period considered (1962-2014), 3 characteristics per year for vacuum cleaners (2007-2014), and 3 new characteristics per year for GPS (2007-2014). Table 1 summarizes the frequencies of occurrence of the new features.

Further descriptive elements are provided below for our four types of products.

Mobile phones: The first test in the French consumer report "Que Choisir" includes the first 14 significant characteristics of mobile phones in 1996, and the following tests add new characteristics. The frequency of the emergence of new characteristics reaches an average of 6 new characteristics per year over a 17-year period (1996-2014). The graph below (figure 6) illustrates the emergence of the new characteristics.

Irons: The first test (December 1962) identifies the first 15 significant characteristics that compose the iron, and the following tests provide new characteristics. The graph below (figure 4) illustrates the emergence of the new characteristics. 
Vacuum cleaners: The first test (1969) provides the first 12 vacuum cleaner characteristics, and the following tests provide new characteristics, which extend the characteristics space of vacuum cleaners over a 44-year period. The graph below (figure 5) illustrates the emergence of the new characteristics.

Global Positioning Systems (GPS) devices: The first test (March 2007) gives the first 18 significant characteristics of GPS devices in 2007, and the following tests provide new characteristics that extend the characteristics space of GPS devices. The graph below (figure 6) illustrates the emergence of the new characteristics.

Cumulated characteristics: Figure 7 shows the total cumulated number of characteristics for our selected consumer goods (Mobile phones, Irons, Vacuum cleaners, and GPS devices). It also shows the rapid and continuing extension of the characteristics space of each product.

We now test hypotheses H1.1 and H1.2.

To test hypothesis H1.1 (and reject H0), we estimate p, the proportion of new characteristics in a one-year period for a given type of product. We estimate $\mathrm{p}$ as the mean of $\mathrm{p}_{\mathrm{ti}+\mathrm{t}}$ measured at each study time $\mathrm{t}_{\mathrm{i}} ; \mathrm{p}_{\mathrm{ti}}=\mathrm{n}_{\mathrm{n}, \mathrm{ti}} /\left(\mathrm{n}_{\mathrm{n}}+\mathrm{n}_{\mathrm{o}}\right)_{\mathrm{ti}}$, where $\mathrm{n}_{\mathrm{n}, \mathrm{i}}=$ the number of new characteristics per year in the time slot that separates study $\mathrm{i}-1$ from study $\mathrm{i} ;\left(\mathrm{n}_{\mathrm{n}}+\mathrm{n}_{\mathrm{o}}\right)_{\mathrm{ti}}=$ the number of characteristics in the consumer report at time ti. We test whether $p$ is significantly different from 0 (t-test at the 5\% level, one-sided). The values and test results are presented below (table 2). The t-test is significant for all four types of products: the average proportion of new characteristics is significantly different from 0 .

Thus far, our results confirm our hypothesis concerning the emergence of new characteristics. Qualitatively, this corresponds to the fact that, over time, mobile phones have been transformed from wireless verbal communication tools into smart devices that people rely upon to organize their lives. GPS devices have been transformed from guides on the road 
to route planners. Vacuum cleaners have been transformed from dust cleaners into autonomous household assistants.

This result invalidates the classical Lancasterian hypothesis: for some products, it is statistically insupportable to contend that the list of characteristics remains constant over time. Moreover, that hypothesis is invalid for periods as short as one year. This hypothesis is also invalid not only for products as innovative as mobile phones but also for products that apparently do not appear to change substantially, such as vacuum cleaners.

Surprisingly, all four product types evolved significantly over time. Intuitively, we would expect that products such as mobile phones would evolve significantly faster than products such as vacuum cleaners and irons. Therefore, we study hypothesis H1.2, which assumes that the emergence of new characteristics differs across products.

We do so by testing the difference between the estimated values for the proportion of new characteristics over a one-year period for each product type. This is a classical comparison test - we first verify that the standard deviation is equal. Then, we check whether the means are different at the 5\% level. The results are provided in table 3 (because there are no significant differences in all standard deviations, we do not provide the details of the test in table 3).

In table 3 , we observe that the proportion of new characteristics over a one-year period can differ significantly across product types. Therefore, H1.2 is confirmed.

For our four products, we conclude that the proportion of new characteristics for the "Mobile phone" category over a one-year period is significantly higher than that for irons. Vacuum cleaners and irons have the same results and cannot be differentiated. "GPS devices" is in an intermediary category: it can neither be differentiated from mobile phones nor from vacuum cleaners and irons.

Thus, we confirm H1.1 and H1.2. New characteristics emerge over time at a 
significant rate, even over a period as brief as one year, and even for products that are apparently stable such as irons and vacuum cleaners. Therefore, the Lancasterian hypothesis cannot be accepted for all types of products. H1.2 indicates that the rate of emergence of new characteristics over a one-year period can differ significantly across product types.

\subsection{Learning process implies interdependency among new characteristics}

Let us check H2. Our empirical studies confirm that new characteristics can be interdependent over time. This mechanism of interdependence allows for the continual emergence of new characteristics. To test this model of overlearning that drives the interdependence among new characteristics, we observe the sequences of new characteristics of consumer goods. Our empirical work allows us to identify the sequences or chain reaction (also known as waterfall) processes that link newly emerging characteristics over time. Doing so confirms the second hypothesis $(\mathrm{H} 2)$, which indicates that during the learning process, the characteristics of consumer goods are not independent over time. We identify waterfall processes that emphasize the learning effect. New characteristics have antecedents and, in turn, influence the appearance of newer characteristics. The figure below (figure 8) summarizes the interdependency among various significant new characteristics for mobile phones.

In the following section, we consider the 'Internet', an example of a chain reaction effect (figure 12), to reveal the mechanism that allows for consumer learning and the launching of new characteristics.

Internet: After the appearance of the Wireless Application Protocol (WAP) in 2000, then GPRS (2003), and UMTS in 2004, we observe that these first Internet characteristics were followed by other characteristics such as EDGE, and 3G. In this case, the consumerlearning process is a chain reaction that allows consumers to learn to use the Internet with a 
mobile phone over time. This waterfall process shows that successive new characteristics define the new function of goods that did not previously exist. Initially, consumers ignored the fact that they could use a phone as an internet-connected computer, but at present, it is nearly impossible to imagine a smartphone without the Internet. Moreover, consumers learned in the unknown, namely, the possibility of using a mobile phone as a computer. This dimension of mobile phones did not initially exist and is instead the result of successive new characteristics. In this case, we can discuss learning in the unknown.

Our two main results complete the evolutionary approach to household consumption that emphasizes the major role of consumer learning in changing consumer wants and preferences. In this paper, concerning consumer learning, we first show that consumers learn the new characteristics of goods in terms of 'novelty'. Second, we emphasize, on the one hand, the role of the interdependency among new characteristics in the 'step by step' learning of consumers. On the other hand, we emphasize the regeneration of the new dimensions of goods. 


\section{Conclusion and discussion}

This work provided empirical material to test and extend the suggestions of the modern evolutionary theory of household consumption behavior. Generally, we suggest that concerning 'novelty', new goods bring new characteristics to the market over time, and consumers learn from these new characteristics. Furthermore, consumers learn about the evolution and enrichment of goods. For example, vacuum cleaners were transformed from dust cleaners to autonomous household assistants. Moreover, we suggest that during the overlearning process, new characteristics of goods create a chain reaction effect because characteristics drive the emergence of newer characteristics. We show that the characteristics of consumer goods follow a generative process.

The results: First, we find that the characteristics space of the four different goods is continuously extended by the addition of new characteristics over time. The emergence of new characteristics is significantly different from 0 (H1.1) and differs across products (H1.2). This result confirms that in the context of novelty, consumers learn the new characteristics of consumer goods, and this learning differs across consumer goods because the frequency of the emergence of new characteristics depends on the type of product. Second, we show that the new characteristics are not independent over time. We identify waterfall processes that emphasize consumer learning patterns, which guarantee the sustainable emergence of new characteristics of consumer goods, and this result confirms our second hypothesis. This result is consistent with a model of "overlearning" in which the regular "imbalance" between consumer wants and product characteristics provokes the regular transformation of products.

Discussion and conclusion: In this paper, we discuss what consumers should continuously learn in the case of 'novelty' or the emergence of new goods and services on the market. We provide a overview of new goods because our empirical research shows that 
consumer goods feature new characteristics over time, which in turn transform the uses and identity of consumer goods.

We should emphasize that our method underestimates the rate at which new characteristics emerge. A more precise observation may reveal new characteristics that emerge over a brief period or in only a specific product niche.

These results are obtained for four products. Other studies may discuss the hypotheses across a larger range of product types. Our method is also currently limited to the product types that were analyzed by the Que Choisir Consumer Guide. More complex products (such as cars) or simpler products (such as shoes or milk, cannot be observed with this "instrument". Further research should help to extend the method to such product types.

Despite these limitations, the results provide some important insights.

1) From an economic perspective, the results indicate that the Lancasterian models of consumption cannot account for the evolution of certain products. Significantly, the results mean that the basic hypothesis of general equilibrium is not valid: Lancaster proposed his model of product characteristics to stabilize a general equilibrium model. This study shows that we need economic models that embed changes in product characteristics, i.e., changes in the basic parameters of the economy.

2) From an epistemological perspective, we tend to assume that objects have a stable definition that changes only marginally. This study shows that, at least for certain products, there is no stability in their economic characteristics (not to mention the evolution of their internal technologies). This result calls for studying new models of objects in which the objects endogenously combine to form a (re)generative system.

3) In particular, we identified a waterfall model of interdependence among characteristics. This model indicates that the dynamics of change are governed by 
learning on both the firm and consumer sides. This learning is of a very specific type:

it does not denote learning to reduce uncertainty (the classical learning model in decision theory); instead, learning consists of generating new wants or new characteristics. This result calls for studying generative logics in firms and by users.

Acknowledgements: This work is a development of part of my doctoral thesis discussed at Ecole des Mines ParisTech in the Management of Science Center (CGS). I wish to thank the members of the chair "Design theory and Methods for innovation" (DTMI) for their interest in my research. I acknowledge financial support from School of Mines ParisTech as part of my doctoral contract.

Conflict of Interest: We have no conflict of interest. 


\section{REFERENCES}

Aghion P, Howitt P (1992) A model of growth through creative destruction. Econometrica 60:323-51.

Arrow KJ (1962) The economic implications of learning by doing. Rev Econ Stud 29:155173

Babutsidze Z (2011) Returns to product promotion when consumers are learning how to consume. J Evol Econ 21:783-801

Bartels DM, Johnson EJ (2015) Connecting cognition and consumer choice. Cognition $135: 47-51$

Becker MC, Knudsen T, March JG (2006) Schumpeter, winter, and the sources of novelty. Ind Corporate Change 15:353-371

Becker MC, Knudsen T, Swedberg R (2012) Schumpeter's theory of economic development: 100 years of development. J Evol Econ 22:917-933

Bunzeck N, Düzel E (2006) Absolute coding of stimulus Novelty in the human Substantia Nigra/VTA. Neuron 51:369-379

Coombs R, Narandren P, Richards A (1996) A literature-based innovation output indicator. Res Policy 25: 403-413

Cowan R, Cowan W, Swann P (1997) A model of demand with interactions among consumers. Int J Ind Organ 15:711-732

Dosi G (1982) Technological paradigms and technological trajectories: a suggested interpretation of the determinants and directions of technical change. Res Policy $11: 147-162$

Dosi G, Freeman C, Nelson RR, Silverberg G, Soete L (eds) (1988) Technical change and economic theory. Pinter, London 
Encinar M, Muñoz F (2006) On novelty and economics: Schumpeter's paradox. J Evol Econ $16: 255-277$

Freeman C, Soete L (1997) The economics of industrial innovation. Pinter, London

Houdé O (2000) Inhibition and cognitive development: object, number, categorization, and reasoning. Cogn Dev 15:63-73

Houdé O, Borst G (2014) Measuring inhibitory control in children and adults: brain imaging and mental chronometry. Front Psychol 5:616

Iansiti M, Clark KB (1994) Integration and dynamic capability: evidence from product development in automobiles and mainframe computers. Ind Corporate Change 3:557605

Kahneman D, Tversky A (1972) Subjective probability: a judgment of representativeness. Cogn Psychol 3:430-454

Kleinknecht A, Reijnen JON, Smits W (1993) Collecting literature-based innovation output indicators: the experience in the Netherlands. In: A. Kleinknecht, D. Bain (Eds) New Concepts in Innovation Output Measurement. St Martin's Press. pp 42-84.

Knutson B, Cooper JC (2006) The lure of the unknown. Neuron 51:280-282

Lancaster K (1971) Consumer demand. Columbia University Press, New York

Lancaster K (1966a) Change and innovation in the technology of consumption. The Am Econ Rev 56:14-23

Lancaster KJ (1966b) A New approach to consumer theory. J Polit Econ 74:132-157

Langlois RN (2001) Knowledge, consumption, and endogenous growth J Evol Econ 11:77-93

Metcalfe JS (2001) Consumption, preferences, and the evolutionary agenda. J Evol Econ $11: 37-58$ 
Mowery D, Rosenberg N (1979) The influence of market demand upon innovation: a critical review of some recent empirical studies. Res Policy 8:103-153

Nelson RR (2012) Why Schumpeter has had so little influence on today's main line economics, and why this may be changing. J Evol Econ 22:901-916

Nelson RR (2013) Demand, supply, and their interaction on markets, as seen from the perspective of evolutionary economic theory. J Evol Econ 23:17-38

Nelson RR, Consoli D (2010) An evolutionary theory of household consumption behavior. J Evol Econ 20:665-687

Nelson RR, Winter SG (1982) An evolutionary theory of economic change. Belknap Press, Cambridge

Romer P (1990) Endogenous technical progress. Journal of Political Economy 98: 71-102

Rosenberg N (1982) Inside the black box. Cambridge University Press, Cambridge

Ruprecht W (2002) Preferences and novelty: a multidisciplinary perspective. In: McMeekin

A, Green K, Tomlinson M, Walsh V (eds) Innovation by the demand. Manchester University Press, Manchester. pp 56-74

Ruprecht W (2005) The historical development of the consumption of sweeteners - a learning approach. J Evol Econ 15:247-272

Sanderson S, Uzumeri M (1995) Managing product families: The case of the Sony Walkman.

Res Policy 24:761-782.

Saviotti PP (2001) Variety, growth and demand. J Evol Econ 11:119-142

Schmookler J (1966) Invention and economic growth. Harvard University Press, Cambridge

Schumpeter JA (1934) Theory of economic development. Harvard University Press, Cambridge

Schumpeter JA (2005) Development. J Econ Lit 43:108-120 
Stefano GD, Gambardella A, Verona G (2012) Technology push and demand pull perspectives in innovation studies : Current findings and future research directions. Res Policy $41: 1283-1295$

Witt U (2001) Learning to consume - A theory of wants and the growth of demand. J Evol Econ 11:23-36

Witt U (2009) Propositions about novelty. Journal of Economic Behavior \& Organization $70: 311-320$

Witt U (2010) Symbolic consumption and the social construction of product characteristics. Structural Change and Economic Dynamics 21:17-25 


\section{Figure Captions}

Fig. 1 Overlearning process: new characteristics and new wants

Fig. 2 Sequences of new characteristics

Fig. 3 New characteristics of Mobile phones from 1996 to 2014

Fig. 4 New characteristics of Irons from 1962 to 2014

Fig. 5 New characteristics of Vacuum cleaners from 2008 to 2014

Fig. 6 New characteristics of GPS devices from 2008 to 2013

Fig. 7 The cumulated new characteristics over time (Mobile phones, Irons, Vacuum cleaners, and GPS devices)

Fig. 8 Interdependency between new characteristics: the chain reaction effect - Mobile phones

Fig. 9 Interdependency among new characteristics: the chain reaction effect - Internet navigation with mobile phones 
Tables

Table 1 Selected products from “Que Choisir?” 1962-2013

\begin{tabular}{|c|c|c|c|c|c|}
\hline & $\begin{array}{l}\text { Period of time } \\
\text { (First test } \\
\text { included) }\end{array}$ & $\begin{array}{l}\text { Nbr of years } \\
\text { (First test } \\
\text { excluded) }\end{array}$ & $\begin{array}{c}\text { Nbr of } \\
\text { consumer } \\
\text { guide surveys }\end{array}$ & $\begin{array}{c}\text { Total nbr of } \\
\text { new } \\
\text { characteristics }\end{array}$ & $\begin{array}{c}\text { New } \\
\text { characteristics } \\
\text { per year }\end{array}$ \\
\hline Mobile & 1996-2014 & 17 & 24 & 113 & 6 \\
\hline Iron & $1962-2014$ & 48 & 24 & 81 & 2 \\
\hline Vacuum cleaner & 1969-2014 & 44 & 37 & 124 & 3 \\
\hline GPS & 2007-2014 & 7 & 10 & 21 & 3 \\
\hline
\end{tabular}

Table 2 Testing hypothesis H1.1

\begin{tabular}{|c|c|c|c|c|c|c|}
\hline & $\mathbf{n}$ & $\mathbf{p}$ & $\mathbf{S}$ & $\begin{array}{c}\text { Confidence } \\
\text { interval, } 5 \% \text { lower } \\
\text { bound }\end{array}$ & $\mathbf{t}$ & Significance \\
\hline Mobile & 23 & $18.6 \%$ & 0.163 & $12.66 \%$ & 5.36 & Significant at $5 \%$ level \\
\hline Iron & 23 & $9.9 \%$ & 0.0593 & $7.72 \%$ & 7.83 & Significant at $5 \%$ level \\
\hline Vacuum cleaner & 36 & $17.3 \%$ & 0.200 & $11.57 \%$ & 5.11 & Significant at $5 \%$ level \\
\hline GPS & 9 & $9.1 \%$ & 0.089 & $3.26 \%$ & 2.90 & Significant at $5 \%$ level \\
\hline
\end{tabular}

Note: The table reports $\mathrm{p}$, the average proportion of new characteristics over a one-year period for all four types of products. $\mathrm{s}$ is the standard deviation of $\mathrm{p}$. We give the lower bound of the confidence interval and the value of a t-test where the hypothesis " $p$ is equal to 0 " is compared with the hypothesis " $\mathrm{p}$ is significantly superior to 0 ". For all four product types, we can reject the hypothesis at the $5 \%$ level - which means that the average proportion of new characteristics is significantly greater than 0 . 
Table 3 Testing hypothesis H1.2

\begin{tabular}{|c|c|c|c|c|}
\hline & & & \\
\hline & & Iron & Vacuum cleaner & GPS \\
\hline \multirow[t]{3}{*}{ Mobile } & t-value & 2.37 & 0.27 & 1.61 \\
\hline & Threshold, 5\%, dof: $n 1+n 2-2$ & 2.02 & 2.01 & 2.045 \\
\hline & Difference? & Significant & Non-significant & Non-significant \\
\hline \multirow[t]{3}{*}{ Iron } & t-value & & 1.70 & 0.29 \\
\hline & Threshold, 5\%, dof: n1+n2-2 & & 2.03 & 2.04 \\
\hline & Difference? & & Non-significant & Non-significant \\
\hline \multirow[t]{3}{*}{ Vacuum cleaners } & t-value & & & 1.17 \\
\hline & Threshold, 5\%, dof: $\mathrm{n} 1+\mathrm{n} 2-2$ & & & 2.02 \\
\hline & Difference? & & & Non-significant \\
\hline
\end{tabular}

Note: We test the difference between the proportion of new characteristics over a one-year period for pairs of product types. For each pair, we compute the t-value that corresponds to the difference between the proportions; we then compare this t-value to the threshold at the $5 \%$ level with $n_{1}+n_{2}-2$ degrees of freedom $\left(n_{1}\right.$ and $n_{2}$ being the sample size for products 1 and 2 in the pair). This method tests whether the difference is significant. 
Figures

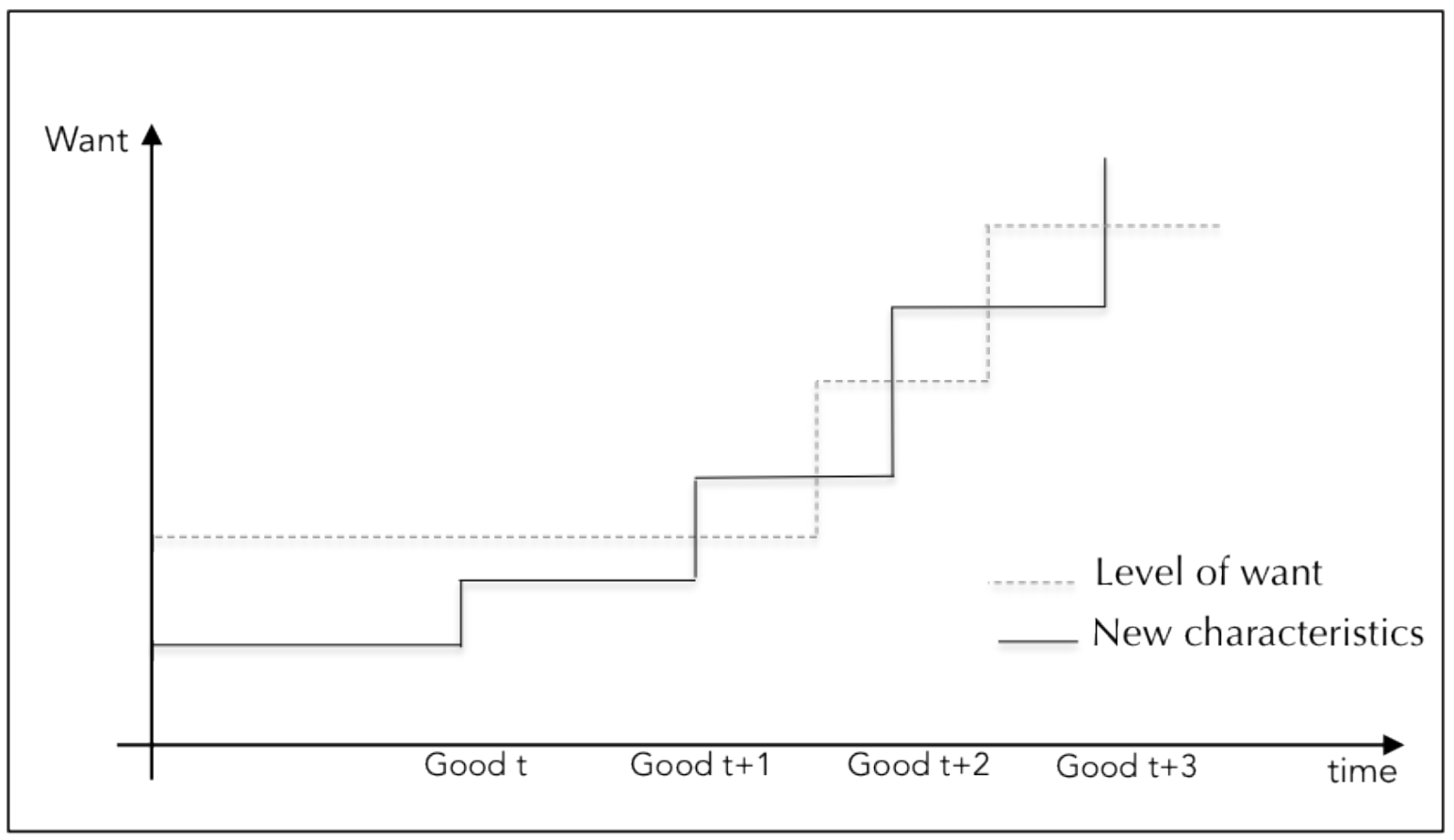

Fig. 1

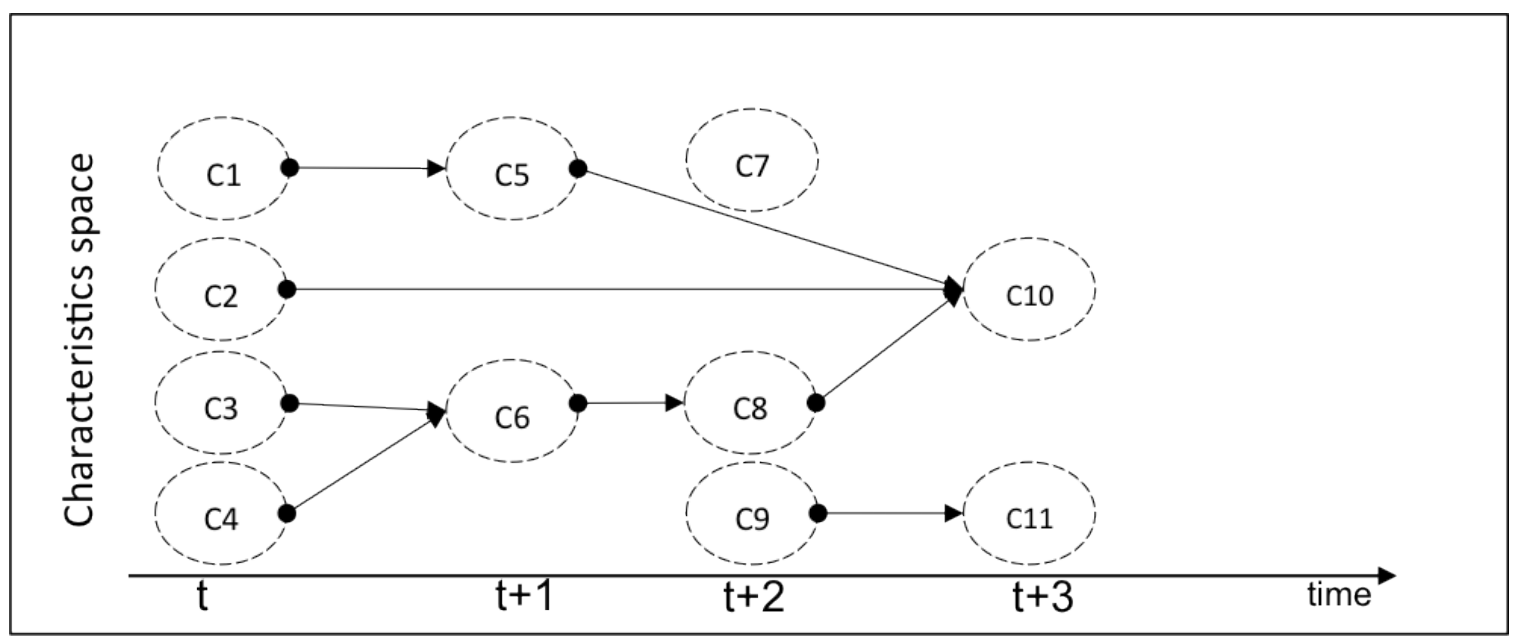

Fig. 2 


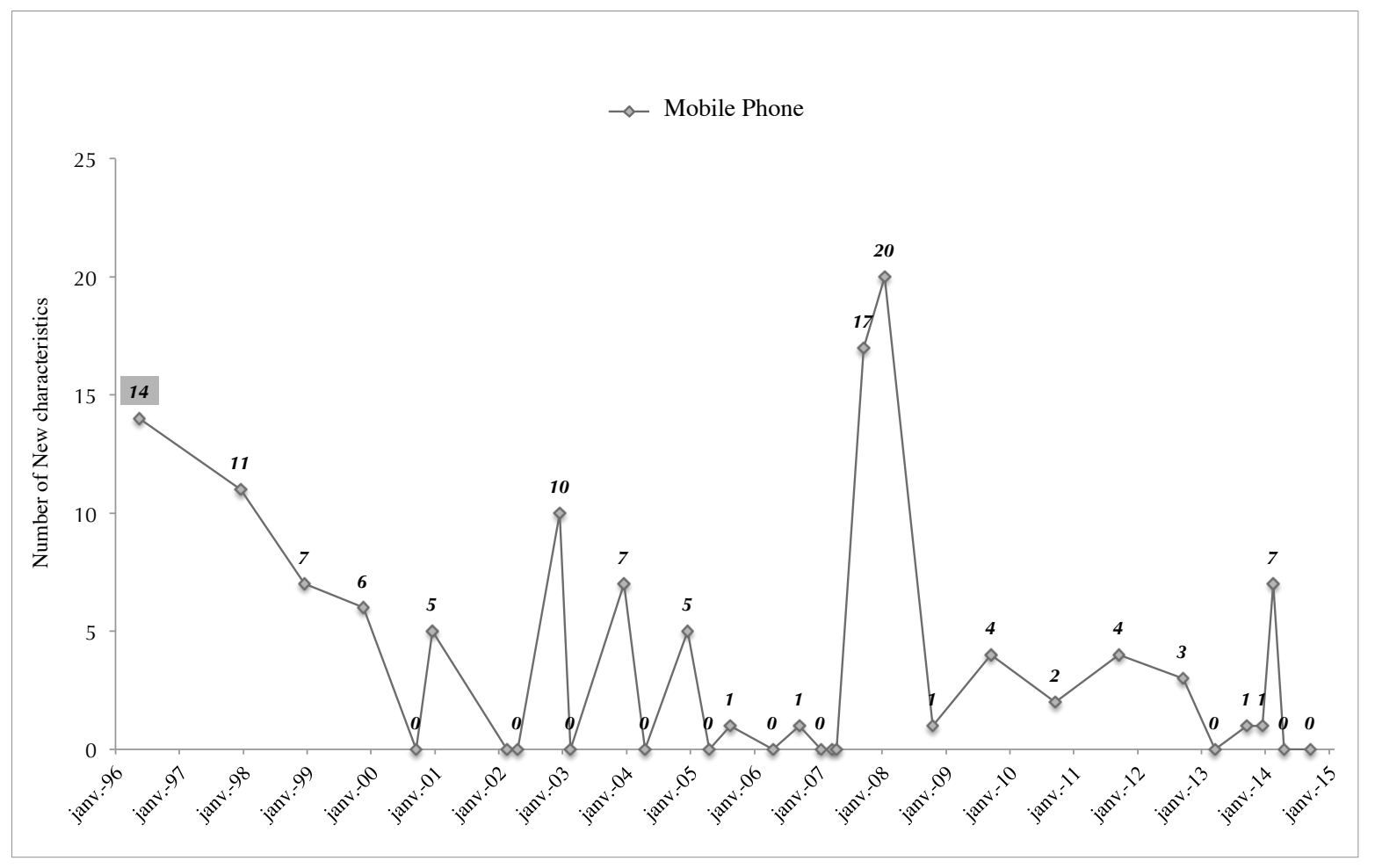

Fig. 3

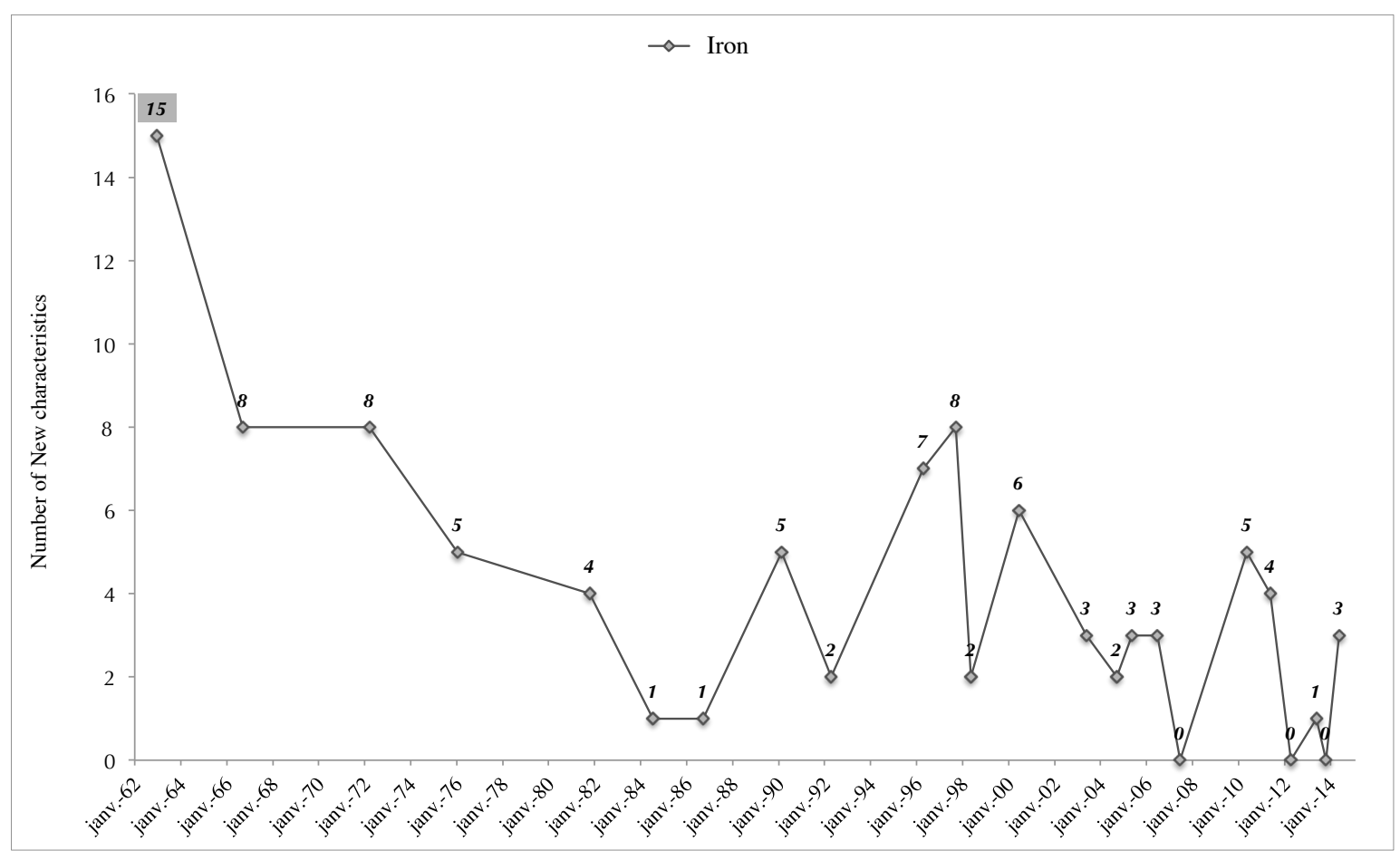

Fig. 4 


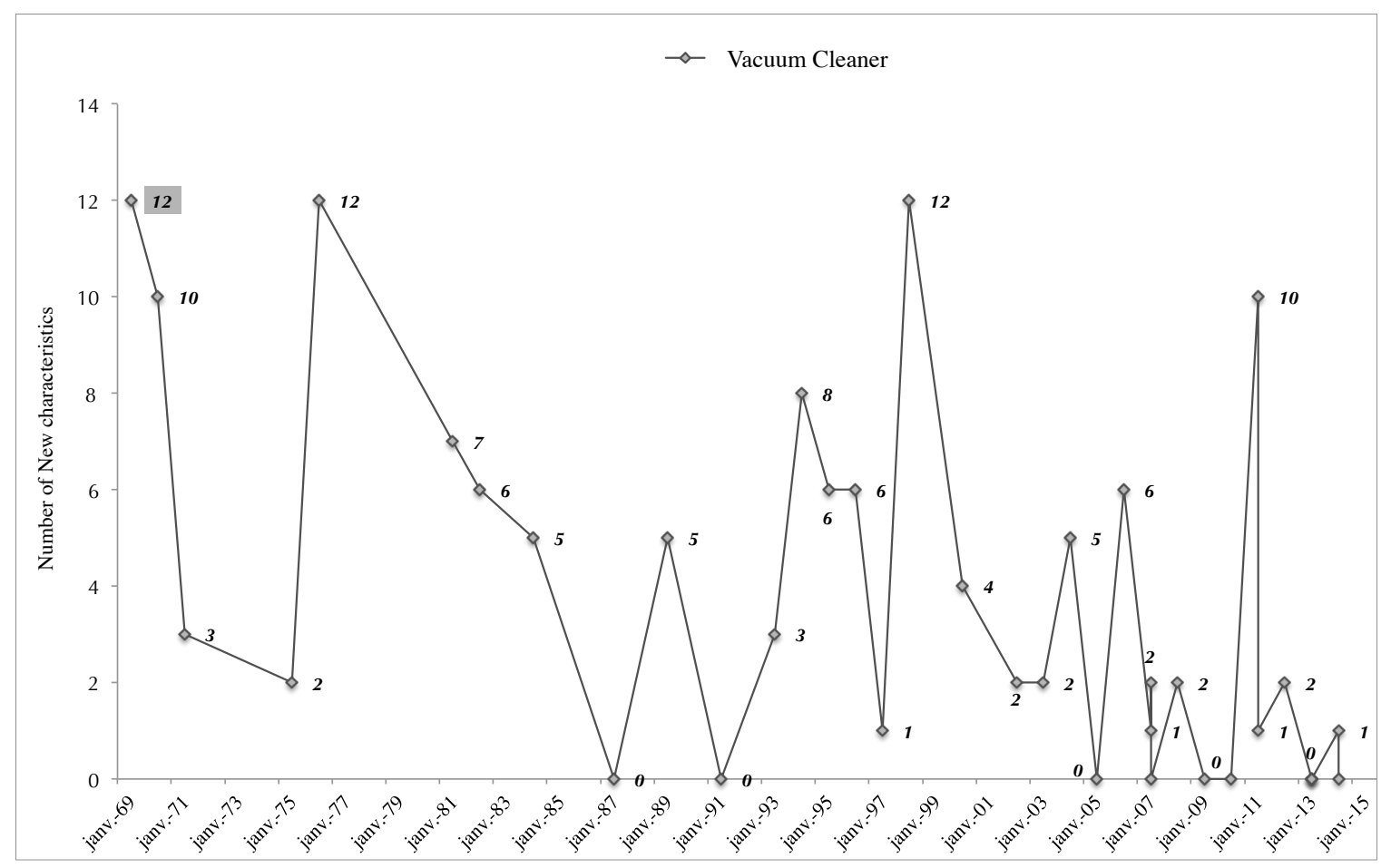

Fig. 5

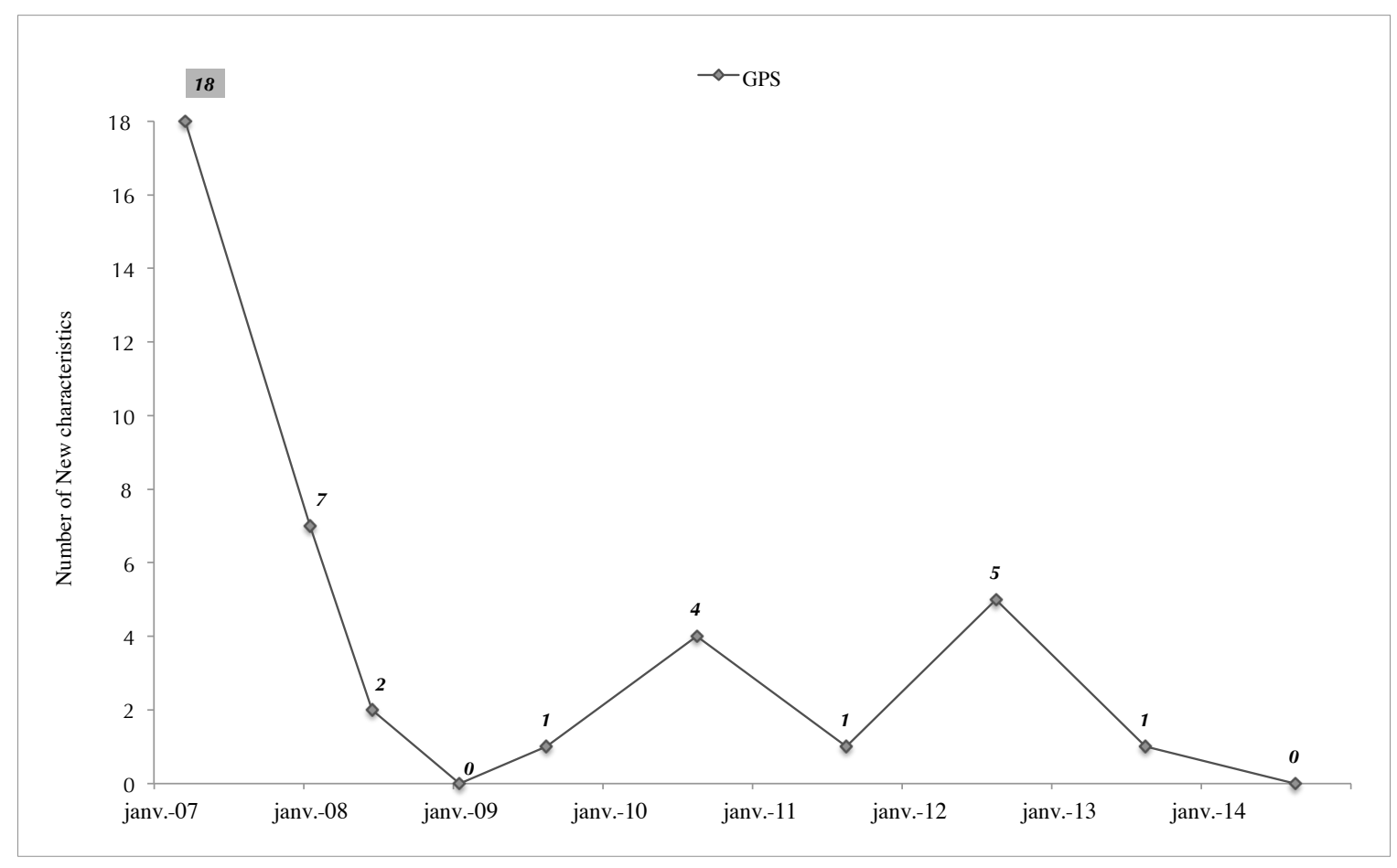

Fig. 6

41 


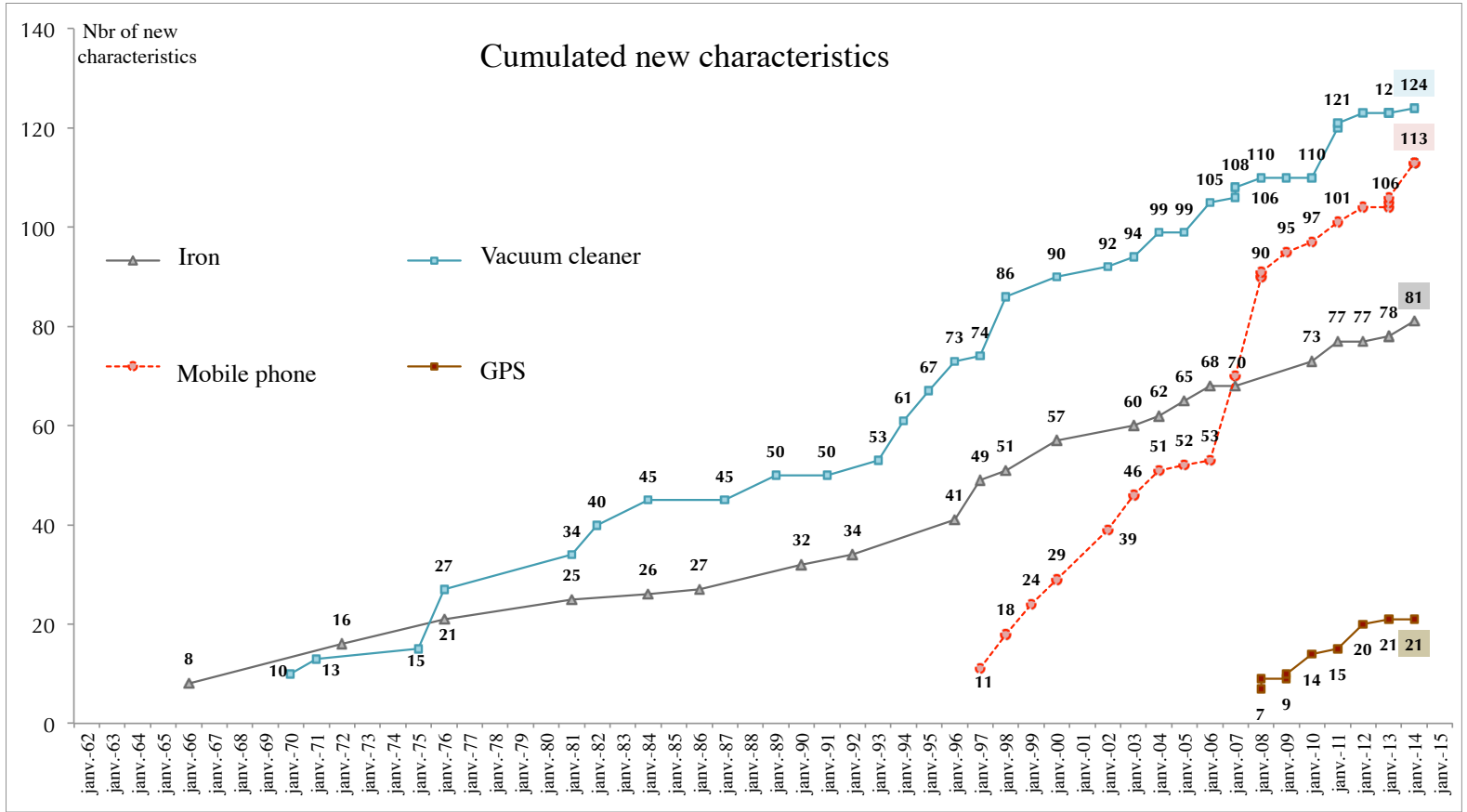

Fig. 7

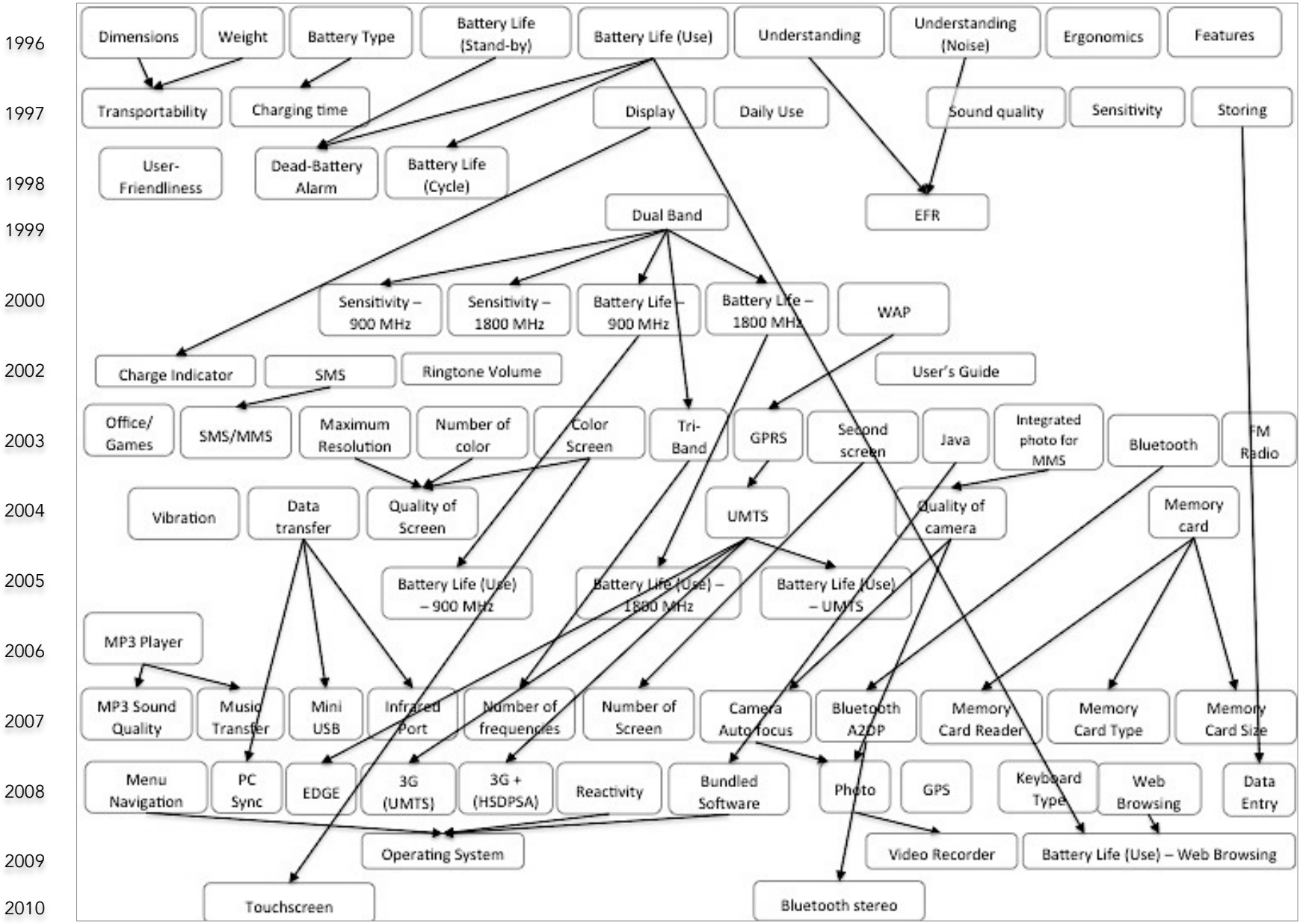


Fig. 8

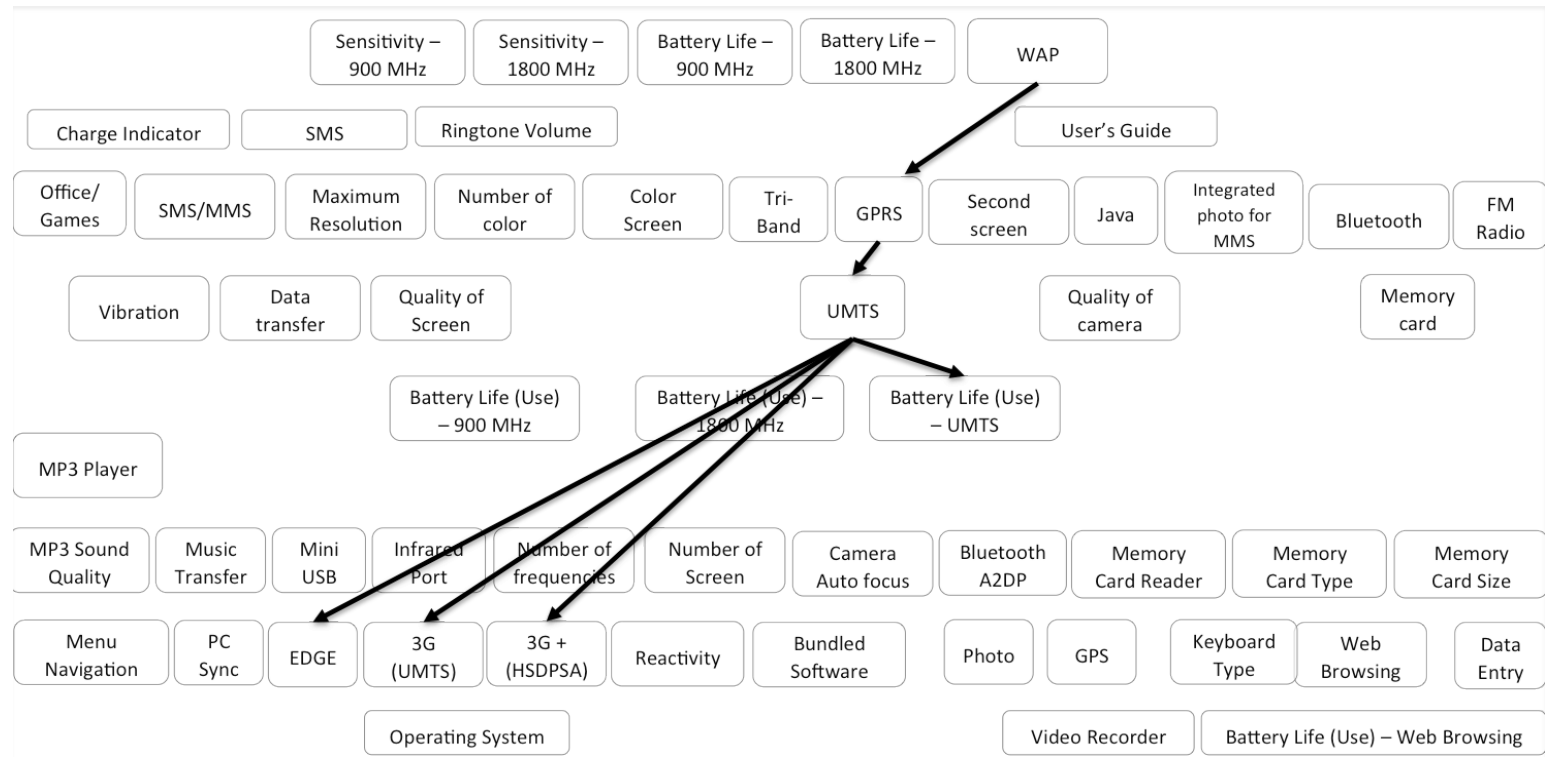

Fig. 9 